\title{
An Outlook for Interaction Experience in Next-generation Television
}

\author{
Sung Woo Kim \\ Centralized Research Lab, Advanced Institute of Technology, KT, 17 Woomyun-dong, Seoul, 137-792
}

\begin{abstract}
Objective: This paper focuses on the new trend of applying NUI(natural user interface) such as gesture interaction into television and investigates on the design improvement needed in application. The intention is to find better design direction of NUI on television context, which will contribute to making new features and behavioral changes occurring in nextgeneration television more practically usable and meaningful use experience elements. Background: Traditional television is rapidly evolving into next-generation television thanks to the influence of "smartness" from mobile domain. A number of new features and behavioral changes occurred from such evolution are on their way to be characterized as the new experience elements of next-generation television. Method: A series of expert review by television UX professionals based on AHP (Analytic Hierarchy Process) was conducted to check on the "relative appropriateness" of applying gesture interaction to a number of selected television user experience scenarios. Conclusion: It is critical not to indiscriminately apply new interaction techniques like gesture into television. It may be effective in demonstrating new technology but generally results in poor user experience. It is imperative to conduct consistent validation of its practical appropriateness in real context. Application: The research will be helpful in applying gesture interaction in next-generation television to bring optimal user experience in.
\end{abstract}

Keywords: Television, Smart TV, IPTV, Interaction, User experience

\section{Introduction}

2007년 아이폰이 세상에 나오면서 모바일 분야는 스마트 (smartness)로의 빠른 물결을 타고 급진적인 패러다임의 변화를 거치게 되었다. IDC의 2012년도 1 분기 세계 휴대폰 시장 동향의 조사에 따르면 출하량 기준으로 스마트폰은 전 세계 휴대폰 시장의 $37 \%$ 를 차지하고 있으며 전년 동기대비 $42.5 \%$ 성장하였다. 또한 스마트폰은 모바일 생태계를 구축 하며 새로운 IT 환경의 주역으로 자리잡았다.

모바일 분야에서의 이런 패러다임은 다른 IT 영역에도 지대한 영향을 미쳤다. 특히 휴대폰 보다는 발전의 속도가 상대적으로 느렸던 TV 역시 스마트 돌풍을 타면서 패러다
임의 진화를 시작했다(Song, M.J., 2010). 2011년 CES에 삼성전자, LG전자, 소니와 같은 글로벌 TV 제조 업체들이 앞다투어 스마트 TV를 선보였고 구글은 모바일 분야의 안 드로이드 플랫폼 열풍을 TV에 이어갈 목적으로 구글 TV 플랫폼을 발표하고 이를 탑재한 제품을 로지텍, 소니를 통해 선보였다. 구글 TV 1.0 은 비록 시장에서 성공하지는 못하였 으나 TV가 어떤 방향으로 진화해 갈지를 보여주는 좋은 사 례였으며 구글은 여전히 TV 분야의 플랫폼 진출을 포기하 지 않아 2012년에 구글 TV 2.0에 해당하는 신제품을 LG 전자와 함께 개발하였다.

$\mathrm{TV}$ 에서의 스마트 돌풍은 일방향적으로 방송 콘텐츠의 소 비만을 목적으로 했던 기존의 TV에서는 전혀 볼 수 없었던 새로운 차원의 경험을 열게 되었다. TV 전용 앱(app)의 등

Corresponding Author: Sung Woo Kim. Centralized Research Lab, Advanced Institute of Technology, KT, 17 Woomyun-dong, Seoul, $137-792$. Mobile: +82-10-9888-6052, E-mail: caerang@gmail.com Copyright@2012 by Ergonomics Society of Korea(pISSN:1229-1684 eISSN:2093-8462). All right reserved.

(c) This is an open-access article distributed under the terms of the Creative Commons Attribution Non-Commercial License(http://creativecommons.org/licenses/by-nc/3.0/), which permits unrestricted non-commercial use, distribution, and reproduction in any medium, provided the original work is properly cited. http://www.esk.or.kr 
장, TV에서의 풀브라우징형 윕서핑 (full-browsing Web surfing) 등이 차세대 TV에서 제공되는 새로운 경험들의 대표적인 예이다(Park, J.B., 2011; Jeong, K.S., 2011).

이런 새로운 차원의 경험을 원활하게 제공하기 위해서 $\mathrm{TV}$ 는 전통적인 리모콘이 가진 제약을 뛰어넘는 새로운 입 력 방식이 필요하게 되었다. 기존의 리모콘으로는 효율적인 텍스트 입력이나 자유로운 커서 조작 등이 매우 어렵기 때 문이다. 이러한 니즈의 발생으로 HCI(Human-Computer Interaction)의 여러 기술들이 TV에 도입되기 시작하였으며 여러 실험적 적용이 연구 또는 제품 차원에서 소개되었다. 특히 NUI(Natural User Interface) 계열의 음성 인식, 얼 굴 인식, 제스처 인식이 TV와의 접목을 적극적으로 시도하 고 있다.

시장의 니즈에 따른 명확한 상업적 활용은 이러한 기술의 발전을 가져오고 있으며 갈수록 보다 진보한 NUI 기술을 탑재한 TV 제품/서비스가 나올 것으로 예측된다. 다만 이런 기술들의 적용이 무조건 사용 경험을 풍부(enrich)하게 해 준다고 단정지을 수는 없다. 과거에 나온 여러 UX의 사례에 서도 잘 알 수 있듯 기술의 발전에 따른 무분별한 적용과 시기 상조적 도입은 막상 사용자의 기대치나 이미 가지고 있 는 심성 모형(mental model) 과의 호환성(compatibility) 과 잘 부합하지 못하여 실패할 여지가 많기 때문이다. 즉, "기 술력이 있기에 구현했다" 식의 단순한 기술 과시성(showoff) 의도에서 시급하게 만들어진 UX는 사용자에게 환영 받 지 못하는 경우가 많다는 것이다.

이러한 문제점을 해결하기 위해서 새로운 입력 기술들을 어디에 어떤 식으로 적용해야 TV에서 사용자의 경험을 최적 화할 수 있는지를 심도 있게 조사하는 UX 연구가 필요하다.

\section{Research Overview}

이 논문은 먼저 차세대 TV의 UX가 어떤 발향으로 발전 하고 있는지에 대한 전반적인 동향을 살펴보고 그런 UX의 발전 방향을 지원하기 위해 어떤 NUI 기술들이 도입되는지 를 자세하게 소개한다.

그 후 앞 장에서 소개한 NUI 중에서도 제스처 인터랙션에 초점을 맞추어 TV 사용자에게 어떤 유용한 인터랙션 경험 (interaction experience)을 줄 수 있는지에 대한 조사 내용 을 기술한다.

이를 위해 먼저 XBox 360의 키넥트(Kinect, Figure 1) 와 같은 카메라 기반의 제스처 인식 기술이 TV에 탑재되었 을 때 나올 수 있는 사용 경험을 브레인스토밍 방식으로 도 출하였다. 이렇게 도출한 사용 경험들 간의 상대적 적합도를
$\mathrm{AHP}$ 기법으로 분석하였다. AHP 분석을 하기 위해 총 8명 의 TV UX 전문가에게 설문 조사를 시행하였다. 본 연구 에서 말하는 적합도란 영어로 "make sense", "reasonable", "practically usable"에 해당하는 것으로 제스처 인터랙션을 적용한 것이 과연 사용자에게 실제적으로 유용하고 의미 있 으며 실용성과 편의성을 제공하는가를 의미한다.

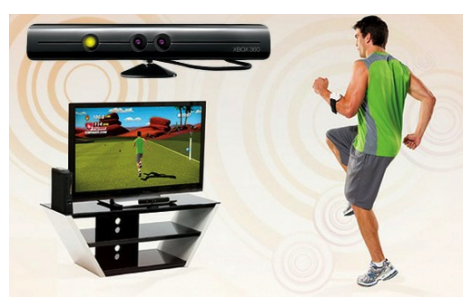

Figure 1. Microsoft XBox 360 \& Kinect

\section{Next-generation TV}

아직까지 차세대 TV가 어떤 것인지에 대한 정확한 학계/ 산업계적 정의는 내려지지 않았다. 현재는 각 기업에서 제각 기 다른 정의를 바탕으로 다른 사양들을 탑재한 제품/서비스 를 "스마트"라는 타이틀을 붙여 시장에 선보이는 과도기적 상황이다(Yun, M.W., 2012). 본 논문에서는 차세대 TV를 기존의 TV와 경험적 차원을 달리 하는 $\mathrm{TV}$ 로 정의한다. 화 질의 개선, 리모콘의 사용성 또는 디자인적 진보와 같이 기 존의 TV에서도 꾸준히 진행되어 경험의 개선과 달리 스마 트에 입각하여 전혀 새롭고 혁신적인 경험을 제공하는 $\mathrm{TV}$ 로 모바일 분야에서 피처폰 대비 스마트폰의 UX가 차원을 달리 하는 것과 유사하다.

IPTV, 스마트 TV, OTT (Over-the-Top) 등이 차세대 TV에 해당하는 제품/서비스이다. 이 밖에도 흔히 거실에 설 치해 두고 쓰는 전통적 개념의 TV를 벗어나 스마트폰이나 스마트패드에 앱(app) 형태로 제공되는 모바일 TV도 차세 대 TV에 들어간다. 국내외의 대표적인 차세대 TV와 그들 의 동향을 살펴보면 다음과 같다.

-IPTV: 국내의 통신사에서 제공하는 IPTV로 KT의 olleh $\mathrm{tv}, \mathrm{LG} \mathrm{U}+$ 의 U+ TV와 SK 브로드밴드의 Btv가 있다. 지난 2008년 실시간 IPTV 서비스의 출범 이후 3년간 IPTV의 가입률은 상승세로 2012년 들어와 500만 가입자 를 넘었다. IPTV 산업의 매출규모 역시 2009년에 비해 10 배 성장한 것으로 추정된다. IPTV는 $\mathrm{VOD}$ 시장에서 
10만 여편이 넘은 콘텐츠(olleh tv 기준)를 갖추어 콘텐츠 경쟁력 측면에서 다른 차세대 TV들에 비해 상당한 우위를 차지하고 있다. 실시간 방송 채널 개수에서도 KT의 OTS (olleh tv skylife)를 보면 전체 채널 183개로 디지털 케 이블의 대표적 기업인 $\mathrm{CNM}$ 의 190개 채널에 밀리지 않는 다. IPTV는 VOD가 주된 사업 모델인 만큼 태생부터 TV 보다 고수준의 상호작용성을 갖추고 나왔다. 2011년부터 $\mathrm{TV}$ 계에 불어온 스마트 열풍으로 각 IPTV 서비스 제공자 마다 스마트 IPTV를 기획하거나 시장에 내놓은 상태인데 웹브라우징, TV 앱스토어, 위젯(widget)형 양방향 서비스 등을 제공한다.

- 스마트 TV: TV 제조사 중심으로 나오는 차세대 TV이다. 세계 TV 시장을 주도하는 삼성전자와 LG전자에서 경쟁적 으로 스마트 TV를 내놓고 있다(Figure 2). 스마트 TV는 기존의 TV와 달리 자체적으로 콘텐츠를 탑재하거나 TV 앱 형태로 콘텐츠 제공 업체의 콘텐츠를 접근할 수 있는 길을 열어둠으로써 기존 TV(legacy TV)가 지상파나 케이 블 서비스 같은 컨텐츠 유통 경로에 묶여 있던 종속성으로 부터 점차 벗어나고 있다. 이는 TV 제조사가 TV의 콘텐 츠 유통까지 겸하는 새로운 형태로 기존의 방송 미디어 가 치 사슬을 흔들고 있다. 스마트 TV 역시 웹브라우징, TV 앱스토어 등의 새로운 경험을 제공한다.
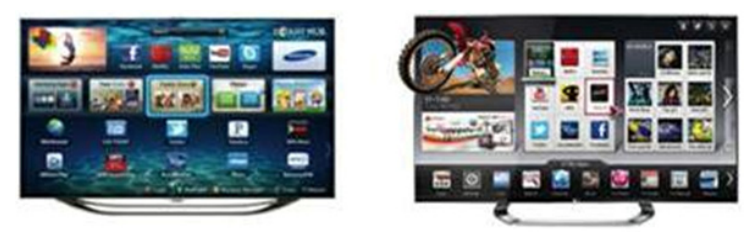

Figure 2. Samsung UN55ES8000F \& LG 55LM9600

- 구글 TV: 구글은 모바일 분야에서 안드로이드 플랫폼의 성공을 TV로 확장하려는 의도에서 2010년에 안드로이드 OS와 Chrome 브라우저에 기반한 구글 TV 플랫폼을 선 보였다. 구글 TV 플랫폼을 탑재한 구글 TV 1.0은 로지텍 과 소니에서 내놓았다. 구글 $\mathrm{TV}$ 는 구글의 뛰어난 검색 기 능과 Web 기반 TV라는 혁신적 사용 경험을 갖추었으나 방송 미디어 기업들과의 불화 등으로 시장에서 성공하지 못하였다. 그렇지만 구글은 구글 $\mathrm{TV}$ 플랫폼 2.0 제품을 LG전자 등과 다시 기획하여 2012년에 시장에 선보였다 (Figure 3).

-OTT(Over-the-Top): OTT는 미디어 분야의 제도권인 방송사와 통신사가 아닌 제 3의 TV나 $\mathrm{VOD}$ 서비스 제

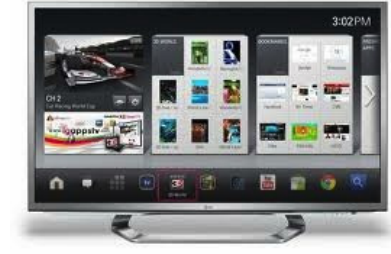

Figure 3. LG Google TV

공 업체를 가리키는 신조어이다. 대표적인 예로 애플사의 Apple TV, 2000년 DVD 우편 렌탈 사업으로 시작하여 현 재는 미국 최대의 온라인 VOD 서비스를 제공하는 Netflix, 세계 최대의 UCC 사이트인 YouTube 등이 있다. OTT는 Apple TV처럼 셋탑박스(settopbox)를 직접 제작하고 전 용 콘텐츠를 유통하는 형태도 있고 Netflix처럼 순수하게 콘텐츠 서비스만 하는 형태도 있다. 순수하게 콘텐츠만 제 공하는 기업은 시장에 나와 있는 여러 단말기에 자신들의 서비스를 포함시키는 방법으로 소비자에게 접근하고 있다. 이를테면 Netflix는 XBox와 같은 게임 콘솔, Apple TV와 같은 셋탑박스 기반의 다른 OTT, 구글 TV 등에 VOD 서 비스를 제공한다. 국내는 주로 컴퓨터/웹 기반의 UCC 업 체들이 OTT 시장을 형성해 왔으며 2012년에 다음커뮤니 케이션에서 셋탑박스 형태의 디지털 방송 서비스인 다음 $\mathrm{TV}+$ (Figure 4)를 시장에 선보였다. OTT는 아직 주류 (mainstream)급 차세대 TV 서비스로서의 위상을 갖추지 는 못했으나 IT에 익숙한 젊은 층을 중심으로 기존의 TV 서비스를 대체하는 신규 서비스로 자리잡아 가고 있다. 이 런 현상을 cord-cutting이라 부르는데 소비자들이 OTT 를 이용하게 되면서 기존의 케이블 TV를 해지한다는 것을 의미하는 상징적인 표현이다.

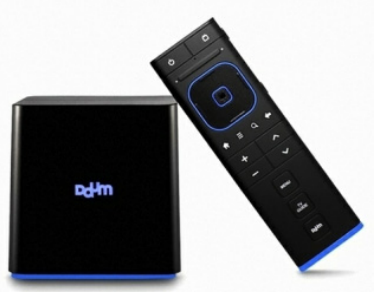

Figure 4. Daum TV+

\section{The Evolution of TV UX}

기존의 TV는 단순한 일방향성 방송 미디어 소비 도구였 
다. 즉, 지상파나 케이블 등의 유선에서 전송되는 실시간 방 송 또는 비디오 플레이어와 같이 외부 입력으로 연결되어 있는 기기에서 재생되는 동영상 콘테츠를 소비자에게 일방 적으로 전달하는 기기였다. 특히 실시간 방송의 소비 도구로 서의 TV의 이미지는 오랫동안 확고하게 사용자들의 머리 속에 심성 모형으로 자리잡고 있었다.

$\mathrm{TV}$ 및 방송 기술은 주로 화질과 전송 방식의 개선 중심 으로 계속 발전해 왔는데 이를테면 흑백에서 컬러로 바뀌고 $\mathrm{SD}$ 의 낮은 해상에서 $\mathrm{HD}$ 의 고해상도로 바뀐 것들이며 앞서 말한 사용 경험 측면에서의 TV의 역할은 오랫동안 큰 변화 가 없었다. UI의 도전 사안으로 리모콘의 사용성 개선이 대 부분 가장 큰 위상을 차지했고 그 다음으로 $\mathrm{TV}$ 설정에 관 련한 단말기 UI의 디자인이었다(Ju, G., 1994).

비교적 최근인 2000년에 들어오면서 TV의 UX에 기존의 도전 사안을 너머선 새로운 이슈들이 나타나기 시작했다. 개 인화를 통한 사용의 편의성을 추구한다든가 멀티미디어 개 념이 TV에 도입된 것이 첫 시작이었는데, 사진 보기, 음악 재생과 같은 방송/동영상 콘텐츠 소비 이외의 콘텐츠 소비에 대한 지원이 기본 내장 어플리케이션(built-in application) 형태로 TV에 탑재되기 시작했다(Lekakos, G., et al., 2001). 2000년대 후반에는 인터넷 연결성이 TV에 도입되면서 비 로소 "일방향성 실시간 방송 미디어 소비 도구"라는 TV UX 의 전통적 심성 모형에 진화의 조짐이 나타났다. 인터넷과 연결되는 TV를 커넥티드 TV(connected TV)라고 불렀는 데 커텍티드 TV는 위젯(widget) 형태로 주식이나 날씨 정 보를 보여주는 비교적 간단한 수준의 양방향 서비스를 제공 했다.

TV UX의 혁신적 패러다임 변화는 모바일 분야의 스마트 의 열풍이 본격적으로 도입되기 시작한 2010년부터 시작되 었다. 커넥티드 TV와 이름을 달리하는 스마트 TV라고 불리 는 차세대 텔레비젼이 등장하면서 TV는 실시간 방송을 보 여주는 단순 콘텐츠 소비 도구를 너머 이전의 TV에는 전혀 존재하지 않았던 각종 새로운 기능과 사용 경험을 적극적으 로 탑재하기 시작했다(Lee, K.H., et al., 2010). 다음은 스 마트 개념이 도입된 차세대 TV에서의 UX 진화의 핵심 요 소들이다.

- Lean-back $\rightarrow$ Lean-forward

- 일방향성 $\rightarrow$ 양방향성

- 적은 상호작용성 $\rightarrow$ 높은 상호작용성

-실시간 방송 시청 $\rightarrow$ 다양한 동영상 시청

- 동영상 콘텐츠 중심 $\rightarrow$ 다양한 콘텐츠로 확대

- 폐쇄성 $\rightarrow$ 개방성

• 단순 독립 기기 $\rightarrow$ 플랫폼 \& 생태계
Lean-back $\rightarrow$ Lean-forward: TV의 전통적 심성 모형 은 lean-back이다. 영어의 "couch potato"란 표현에서도 알 수 있듯 TV 시청자의 전형적인 행태는 "거실의 소파에 뒤로 푹 기대어 앉거나 누워 리모콘을 들고 TV 보기"이다. 전통적 TV와 달리 차세대 TV는 각종 양방향성 서비스와 높은 수준의 상호작용성을 가지고 사용자의 능동적 참여를 적극적으로 유인한다. Lean-forward는 차세대 TV에서 사 용자들이 보이게 될 가장 두드러진 행태의 변화이다.

일방향성 $\rightarrow$ 양방향성: 커넥티브 TV에서 위젯 형태로 제 공되던 비교적 단순한 정보의 사실상 일방향적 전달성이 차 세대 TV로 넘어오면서 높은 상호작용성, 개인화 및 지역화 를 통해 한층 강화된 양방향 서비스로 진화하였다. 또한 기 존의 주가나 날씨 이외에도 뉴스, 실시간 교통 정보, 지도 등 다루는 정보의 범주도 한층 넓어졌다.

적은 상호작용성 $\rightarrow$ 높은 상호작용성: 기존의 $\mathrm{TV}$ 에서의 상호작용은 제한적이었으며 주로 채널 변경, 소리 변경, 외 부 입력 변경 정도로 케이스도 적은 편이었다. 차세대 $\mathrm{TV}$ 에 서는 $\mathrm{TV}$ 전반에 걸쳐 상호작용성이 한층 진화하였다. 이를 테면 VOD 서비스를 제공하는 IPTV는 TV보다 훨씬 높은 수준의 상호작용성을 제공한다. 새로운 기능에서만 높은 상 호작용성이 제공되는 것이 아니다. 채널 변경과 같은 전통적 인 TV 사용 케이스에서도 스마트 EPG(Electronic Program Guide) 와 같이 상호작용성이 한층 강화되었다.

실시간 방송 시청 $\rightarrow$ 다양한 동영상 시청: 기존의 TV에서 영상 콘텐츠 소스(source)는 실시간 방송이 거의 대부분이 었으며 기타 DVD 플레이어와 같이 외부 입력으로 연결된 기기의 영상 콘텐츠 정도가 부가적인 소스였다. 이에 반해 차세대 TV에서는 이들뿐만 아니라 PPV (Pay-per-View), $\mathrm{UCC}, \mathrm{OTT}$ 등 다양한 영상 콘텐츠 소스가 있다. VOD (Video-on-Demand)를 핵심 사업 모델로 하는 IPTV, OTT 뿐만 아니라 TV 제조사에서 직접 넷플릭스(Netflix), 유튜브(YouTube)와 같은 VOD 서비스 제공자들과 제휴를 맺어 자체적으로 영상 콘텐츠를 제공하기도 한다.

동영상 콘텐츠 중심 $\rightarrow$ 다양한 콘텐츠로 확대: $\mathrm{TV}$ 는 원래 영상 중심의 매체이지만 차세대 TV에서는 영상 콘텐츠 이 외의 다른 영역으로까지 콘텐츠 범주를 넓혀가고 있다. 웹 (Web), 각종 양방향 서비스가 제공하는 정보, 전자책, 온라 인 잡지, 사진, 온라인 음악 서비스, 게임, 각종 $\mathrm{TV}$ 앱(app) 등 영상 콘텐츠 이외에 사용자가 즐길 수 있는 콘텐츠의 종 류가 대폭 확장되었다. 새롭게 도입되는 콘텐츠들은 높은 상 호작용성과 양방향성을 갖춰 사용자의 lean-forward 행동 성향을 더욱 부추기고 있다.

폐쇄성 $\rightarrow$ 개방성: TV용 앱스토어 (app store)를 운영하 거나 IPTV에서 일반인에게 UCC용 채널 번호를 부여하는 것에서 알 수 있듯 개방성은 차세대 TV의 핵심 UX 요소이 
다. 특히 TV 제조 업체는 단말기 판매가 주된 사업인 만큼 콘텐츠 영역을 대폭 개방하여 써드파티 콘텐츠 제공자의 참 여를 적극 유도하고 있다. IPTV 서비스 업체는 자신이 보유 한 콘텐츠의 유통으로부터 발생하는 수익이 주된 사업 모델 이라 콘텐츠 개방성에 대해 아직 보수적인 측면이 없지 않아 있지만 갈수록 개방화 하는 추세이며 다른 형식의 콘텐츠 제공에 대해서는 적극적으로 써드파티 서비스 유치와 참여 를 유도하고 있다.

단순 독립 기기 $\rightarrow$ 플랫폼 \& 생태계: 구글 TV의 사례에 서도 알 수 있듯 TV에도 플랫폼형 OS가 탑재되면서 차세 대 TV에서는 플랫폼 기반의 생태계 조성이 가능해졌다. 즉, $\mathrm{TV}$ 가 스마트화 되면서 차세대 TV는 더 이상 거실에 놓여 홀로 쓰이는 독립 기기 (standalone device) 가 아니라 TV 스크린 또는 이보다 확장된 $\mathrm{N}$ 스크린을 중심으로 한 생태계 의 주요 플레이어로 위상을 높여가고 있다.

\section{Interaction Experience for the Evolution of TV UX}

4장에서 설명한 차세대 TV에서의 UX 진화는 필히 입력 /조작 UI의 혁신적 개선이 뒷받침 되어야 한다. 기존의 TV 용 리모콘은 웹 서핑이나 게임과 같은 고차원의 상호작용이 요구되는 새로운 경험을 소화할 수 없기 때문이다. 즉, 차세 대 TV의 새로운 사용 경험이 사용자에게 실제 의미 있고 유용한 경험이 되기 위해서는 TV와 사용자 간의 인터랙션 경험 (interaction experience) 을 담당하는 UI부터 획기적으 로 발전해야 한다(Choi, S.W., et al., 2011; Gu, M.J., 2006; $\mathrm{Kim}, \mathrm{E.J.}$, et al., 2009). 덧붙여 고차원적인 상호작용 경험 에는 전통적인 사용성 뿐만 아니라 상호작용 과정에서의 즐거움과 같은 감성적인 요소도 고려해야 한다(Kim, J.D., 2010).

이러한 이유로 차세대 TV에서는 버튼 중심의 기존 리모 콘을 너머선 새로운 차원의 입력 방식을 적극 도입하게 되 었다. 이런 경향은 특히 스마트 TV에서 많이 볼 수 있는데 $\mathrm{NUI}$ (Natural User Interface) 가 관심의 집중을 받고 있다. 최근 나온 스마트 TV의 사례를 통해 NUI의 적용 동향을 살펴보면 아래와 같다(Bak, J.H., et al., 2011).

LG전자는 자사의 스마트 TV에 매직 리모콘이란 제스처 기반의 리모콘을 제공한다(Figure 5). 매직 리모콘은 완드 (wand)형 제스처 인터랙션을 사용한다. 즉 가속도 센서, 자 이로(gyro) 센서 등이 탑재된 마술봉과 같은 스마트 리모콘 을 들고 $\mathrm{TV}$ 를 조작하는 것이다. 매직 리모콘의 제스처 인터 랙션은 포인팅 (pointing) 과 패턴 인식형 인터랙션으로 구성
되어 있다. 포인팅은 리모콘을 가지고 화면의 커서를 조작하 는 것이고 패턴 인식은 화면에 특정 패턴을 그리면 TV가 그 패턴을 인식하여 명령을 수행하는 것이다. 이 밖에도 매 직 리모콘에는 TV의 기본 조작에 쓰이는 버튼들과 웹페이 지의 스크롤 등에 유용하게 쓰이는 휠(wheel)을 탑재하여 제스처와 전통적인 버튼 인터랙션이 혼합적으로 사용된다. 또한 LG전자의 스마트 TV는 음성 인식도 제공하는데 매직 리모콘에 달려 있는 마이크에 사용자가 음성 인식 모드를 작 동시킨 후 말을 하면 명령어 또는 자연어로 인식한다.

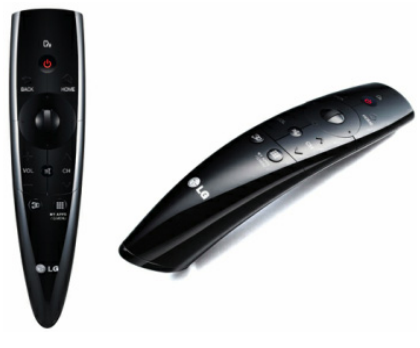

Figure 5. LG Magic Remote

Figure 2에는 삼성전자가 2012년에 선보인 ES8000 스 마트 TV가 나와 있다. 이 스마트 TV는 음성 인식, 동작 인 식 및 얼굴 인식을 이용한 인터랙션을 제공한다. 음성 인식 에서는 사용자가 리모콘이나 TV를 향해 명령어를 말하면 TV가 이를 인식하여 해당 명령을 수행한다. 동작 인식은 매 직 리모콘과는 달리 완드리스(wandless) 형으로 사용자가 자신의 팔을 이용하여 화면의 커서를 조작하는 방식이다. 한 편으로 삼성전자는 스마트 터치 리모콘(Figure 6)이라고 부 르는 터치 패드를 탑재한 리모콘을 통해 별도의 커서 조작 인터랙션 방식을 제공하기도 한다. 또한 얼굴 인식도 되는데 사용자의 안면 인식을 통한 자동 로그인과 같은 사용 경험에 활용된다.

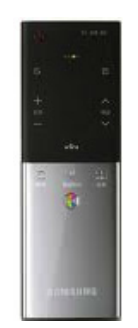

Figure 6. Samsung Smart Touch Remote

이 밖에도 LG전자에서 2012년에 선보인 구글 TV는 뒷 면에 full-QWERTY 키보드를 장착한 매직 리모콘으로 사 
용자가 보다 편하고 빠르게 텍스트를 입력할 수 있게 해준 다. 구글 TV에서 QWERTY 키보드형 리모콘은 구글 TV의 $\mathrm{UX}$ 요구사항이기도 한데 TV에서도 구글의 강력한 검색 서비스를 이용할 수 있도록 하기 위해서이다. QWERTY형 키보드를 탑재한 리모콘은 특히 OTT용 셋탑박스에서 많 이 채택한 방식인데 국내의 다음 $\mathrm{TV}+$ 에서도 볼 수 있다 (Figure 7).
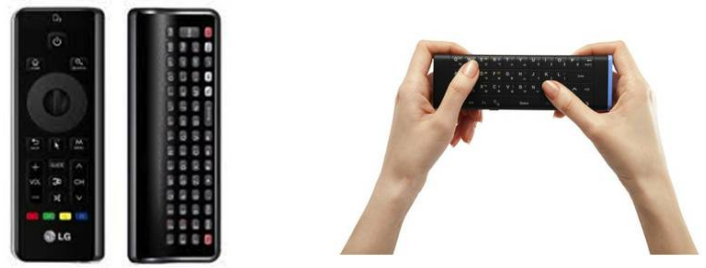

Figure 7. LG Google TV Remote \& Daum TV+ Remote

앞서 말했듯 차세대 TV의 새로운 UX를 위해서는 인터랙 션 경험의 혁신이 반드시 뒷받침 되어야 한다. 현재의 동향 은 NUI를 적극 도입하는 것이다. NUI에서도 음성 인식과 제스처 인식 기술이 주목을 받는데, 제스처 인터랙션은 완드 (wand)형 또는 완드리스(wandless)형으로 화면 상의 커서 를 조작하는 방식을 사용한다. 음성 인식은 애플 아이폰의 시리(Siri) 가 인기를 끌며 대중적 인지도가 올라간 점을 고 려하여 각 제조사에서 경쟁적으로 탑재하였다. 이처럼 NUI 를 적극적으로 활용하면서도 한편으로는 기존 리모콘의 인 터랙션도 함께 발전시키는 전략을 병행 중이다. LG전자의 휠 버튼, 삼성전자의 터치패드형 리모콘 및 구글 TV 2.0 의 QWERTY 키보드 장착 리모콘에서 이런 면모를 볼 수 있다.

\section{Touchless Gesture Interaction on TV}

$\mathrm{NUI}$ 의 도입이 TV UI 혁신의 도화선이 된 것은 사실이다. 그렇지만 UX적 접근에 있어서는 보다 세심한 고려와 주의 가 필요하다.

새로운 기술이 사업적 상황이나 트렌드에 의해 경쟁적으 로 도입될 때 흔히 나오는 UX 문제가 바로 "기술 전시를 위한 UX"이다. 기술력을 자랑하기 위해 억지스럽게 들어간 $\mathrm{UX}$ 라든가 기술이 있기에 그 기술을 굳이 적용하지 않아도 되는 부분까지 과도하게 적용하는 UX가 이런 예인데 새로 운 기술이 적극적으로 활용되는 시점에 종종 발견되는 문제 점이다. 이런 식의 $\mathrm{UX}$ 는 사용자에게 불편함을 초래하거나
아직까지 불안정한 기술로 인해 사용자의 기대치를 만족시 키지 못하여 외면을 받기 쉽다.

본 연구에서는 제스처 인식 기술이 TV의 UX에 적용되었 을 때 어떤 인터랙션 경험이 적합할지에 대해 조사해 보았다. 본 연구가 채택한 기술은 Figure 2에 나온 삼성전자 스마트 TV나 Figure 1의 키넥트와 같이 카메라 기반의 비접촉 제 스처 인식 기술이다.

조사는 TV의 UX 전문가들을 대상으로 $\mathrm{AHP}$ 기법에 의거 하여 설문으로 데이터를 수집한 후 분석하였다. 이를 위해 먼저 카메라 기반의 제스처 인식 기술이 TV에 탑재되었을 때 나올 수 있는 대표적인 사용 경험을 브레인스토밍을 통해 도출하였다(Table 1).

그 다음 도출한 사용 경험들 간의 상대적 적합도에 대해 설문을 통해 데이터를 수집한 후 AHP 기법으로 분석하였다. 설문은 총 8 명의 전문가를 대상을 수행하였으며 기존 $\mathrm{TV}$, IPTV, 스마트 TV의 UX 분야에서 경력을 쌓아온 현업 전 문가들로 구성하였다. AHP 분석을 전제한 설문인 만큼 각 항목마다 Table 1 의 사용 경험을 2 개씩 뽑아 적합도에 대한 쌍대 비교를 하는 형식을 취했다(Figure 8).

Table 1. User experience cases

\begin{tabular}{|c|c|}
\hline Case & Description \& example \\
\hline $\begin{array}{c}\text { Voice } \\
\text { Recognition }\end{array}$ & $\begin{array}{l}\text { Used to trigger voice commander to begin } \\
\text { controlling television via voice } \\
\text { Example) pose the gesture for voice commander } \\
\text { and say "volume up" to raise the volume }\end{array}$ \\
\hline $\begin{array}{l}\text { Channel } \\
\text { Zapping }\end{array}$ & $\begin{array}{l}\text { Used to change channels } \\
\text { Example) pose the gesture for channel zapping } \\
\text { to change the current channel to either next or } \\
\text { previous one }\end{array}$ \\
\hline $\begin{array}{l}\text { Volume } \\
\text { Change }\end{array}$ & $\begin{array}{l}\text { Used to raise or lower the volume } \\
\text { Example) posing the gesture for volume change } \\
\text { will either raise or lower the volume }\end{array}$ \\
\hline $\begin{array}{l}\text { Power } \\
\text { On/Off }\end{array}$ & $\begin{array}{l}\text { Used to turn on or off the television } \\
\text { Example) pose the gesture to either turn it on or } \\
\text { off }\end{array}$ \\
\hline $\begin{array}{l}\text { Web } \\
\text { Browsing }\end{array}$ & $\begin{array}{l}\text { Used to surf the Web on TV } \\
\text { Example) control the pointer on the screen via } \\
\text { gesture to click on the link, scroll up/down a } \\
\text { page, etc,. }\end{array}$ \\
\hline $\begin{array}{l}\text { Text } \\
\text { Entry }\end{array}$ & $\begin{array}{l}\text { Used to enter text through OSK(On-Screen } \\
\text { Keyboard) } \\
\text { Example) On a search pop-up enter "ghost" to } \\
\text { search movies with that title }\end{array}$ \\
\hline $\begin{array}{l}\text { Game } \\
\text { Control }\end{array}$ & $\begin{array}{l}\text { Used to play games running on TV } \\
\text { Example) play a gesture-based TV game app }\end{array}$ \\
\hline
\end{tabular}


Table 1. User experience cases (Continued)

\begin{tabular}{c|l}
\hline Case & \multicolumn{1}{c}{ Description \& example } \\
\hline $\begin{array}{c}\text { VOD } \\
\text { Selection }\end{array}$ & $\begin{array}{l}\text { Used to navigate and select a content from } \\
\text { Content list } \\
\text { Example) Browse through lists of pages showing } \\
\text { VODs and select one to watch it }\end{array}$ \\
\hline VOD & $\begin{array}{l}\text { Used to control video during watching } \\
\text { Example) give a command such as "fast forward", } \\
\text { "rewind", "pause/play", "stop", " skip" via gesture }\end{array}$ \\
\hline Shortcut & $\begin{array}{l}\text { To quickly launch a function } \\
\text { Example) to rapidly bring up the search pop-up, } \\
\text { to quickly check on the weather via weather } \\
\text { information widget, etc,. }\end{array}$ \\
\hline
\end{tabular}

\begin{tabular}{|c|c|c|c|c|c|c|c|c|c|c|c|c|c|c|c|c|c|c|}
\hline \multirow{2}{*}{\multicolumn{18}{|c|}{$\begin{array}{l}\text { [음성 인식 모드]와 [채널 변경] 중 제스처 인터랙션이 더 적합하다고 생각되는 것은? } \\
\text { 음성 }\end{array}$}} & \\
\hline & & & & & & & & & & & & & & & & & & \multirow{2}{*}{$\begin{array}{l}\text { 채널 } \\
\text { 변경 }\end{array}$} \\
\hline $\begin{array}{l}\text { 인식 } \\
\text { 모드 }\end{array}$ & 9 & 8 & 7 & 6 & 5 & 4 & 3 & 2 & 1 & 2 & 3 & 4 & 5 & 6 & 7 & 8 & 9 & \\
\hline
\end{tabular}

Figure 8. An example of the survey question

조사에서 의미하는 적합도란 제스처 인터랙션을 적용한 $\mathrm{UI}$ 가 사용자에게 실제적으로 얼마나 의미가 있는지에 대한 정도이다. 영어 표현을 사용하여 설명한다면 "이 제스처 인 터랙션이 사용자에게 얼마나 make sense, reasonable, practically usable 한가?"이다. 즉, 제스처 인터랙션에 기반 한 UI가 과연 사용자에게 실제적으로 유용하고 의미 있으며 실용성과 편의성을 제공하는가를 기준으로 쌍대 비교 대상 인 두 항목의 상대적 적합도를 따져보는 것이다.

$\mathrm{AHP}$ 분석 결과 상대적 적합도의 순위는 Table 2 와 같이 나왔다.

Table 2. AHP analysis result

\begin{tabular}{c|c}
\hline 1 & Game control \\
\hline 2 & Channel zapping \\
\hline 3 & Web browsing \\
\hline 4 & Volume Change \\
\hline 5 & VOD selection \\
\hline 6 & Shortcut \\
\hline 7 & Voice recognition \\
\hline 8 & VOD control \\
\hline 9 & Power On/Off \\
\hline 10 & Text entry \\
\hline
\end{tabular}

Table 2에서 게임 조작이 1 위로서 가장 적합하다고 나온
것은 카메라 기반의 제스처 인터랙션이 Xbox의 Kinect와 같이 게임 분야에서부터 이용되었고 여전히 게임 분야에서 가장 활성화 되어 있기 때문인 것으로 보인다. 여기로부터 얻을 수 있는 시사점은 다음과 같다: 카메라 기반의 제스처 인터랙션을 사용하는 차세대 $\mathrm{TV}$ 를 보유한 고객은 자연스레 여기서 재생할 게임들은 제스처 인터랙션으로 조작하게 될 것이라 생각할 것이다. 따라서 기본적으로 제공할 게임들은 제스처 인터랙션 기반의 게임으로 구성하는 것이 바람직하 다. 특히 기존 4 방향 키패드 방식의 리모콘을 함께 제품/서 비스와 함께 제공하더라도 게임 어플리케이션만큼은 제스처 인터랙션을 적극 활용해야 한다. 또한 전용 앱스토어에 올라 올 써드파티 제작사의 게임들도 기본적으로 제스처 인터랙 션의 사용을 적극 권장해야 한다.

전통적인 사용 케이스인 채널 변경이 Web browsing을 제치고 2 위를 한 것은 예상 밖의 결과이다. 제스처 인터랙션 이 자유롭게 떠다니는 커서(free-floating cursor)식 조작 을 제공하는 만큼 TV용 Web browsing에 상당히 최적화된 $\mathrm{UI}$ 임을 고려해 볼 때 더욱 그러한데, 한편으로 이런 특징은 차세대 TV에서도 여전히 전문가들은 전통적(legacy) TV의 기본 사양(feature)을 중요하게 여긴다는 것을 의미한다고 할 수 있다. 실제로 또 다른 전통적 사용 케이스인 소리 크 기 변경이 4 위를 차지한 것도 이를 반영한 결과이다. 여기에 덧붙여 채널 변경 (channel zapping)이 위아래로 채널을 바 꾼다는 점에서 손을 위아래로 흔드는 간단한 제스처가 가장 먼저 떠오를 만큼 제스처 인터랙션과 자연스레 잘 맞는다는 점도 있다.

텍스트 입력이 제스처 인터랙션을 사용하기에는 가장 적 합하지 않다는 결론은 텍스트 입력이 여전히 TV에서는 큰 $\mathrm{UX}$ 도전 사안임을 시사한다. 이를테면 암호를 요구하는 로 그인 사용 케이스에서 전통적인 4 방향 키패드 형식의 리모 콘이나 제스처 인터랙션 기반이나 모두 포커스 내지 커서를 스크린 키보드 위에서 조작하는 과정에서 입력하려는 암호 의 조합이 노출된다는 것은 동일하다(일부 스마트 TV는 이 러한 단점을 극복하고자 얼굴 인식이나 음성 인식을 사용자 인증 UX로 사용한다). 차세대 TV 플랫폼 사업에서 각종 첨단의 기능과 경험을 추구하는 구글이 텍스트 입력에서만 큼은 전통적인 QWERTY 키보드를 고집하면서 이를 UX 필 수 요구사항(requirement)으로 정책화 한 것 역시 본 조사 에서 텍스트 입력에 대해 나온 전문가들의 종합적 의견과 일맥상통한다.

기타 브레인스토밍 과정에서 나름대로 상위권에 들어가지 않을까란 예상이 있었던 shortcut와 음성 인식 모드의 시작 은 중위권에 머물렀다.

본 $\mathrm{AHP}$ 조사는 전문가의 주관적인 판단에 따라 사용 케 이스의 상대적 적합도를 결정하는 것이라 어느 정도의 선입 
견은 피할 수 없는 부분이다. 이를테면 각 사용 케이스에 대 한 서로 간의 정의와 구체적 사례가 다를 수 있다는 점이나 전통적 TV에서의 UX 업무 경력 대비 IPTV나 Smart TV 에서부터 쌓은 TV UX의 경력과 같은 개인적인 커리어 차 이가 상대적 적합도의 의사결정에 영향이 있었을 것이다.

한편으로 앞서도 언급하였듯 본 논문에서 다루는 차세대 $\mathrm{TV}$ 가 아직 산업계에서 표준으로 인정받는 정의(definition) 가 내려지지 않았고 이에 따라 각 기업의 연구 과제나 상업 용 제품/서비스가 제각기 다른 사양을 갖추고 등장하는 일종 의 춘추전국시대형 과도기의 상황이 이번 전문가 대상 조사 에 그대로 잘 반영되었을 것으로 사료된다.

\section{Conclusion and Future Study}

오랜 기간 동안 UX적으로 큰 변화 없이 "실시간 방송 또 는 연결된 외부 기기의 동영상을 보여주는 기기"라는 심적 모형을 유지해 왔던 TV는 모바일 분야의 스마트 열풍으로 $\mathrm{UX}$ 의 패러다임 변화를 맞이하게 되었다.

차세대 TV는 기존의 TV에는 전혀 없었던 새로운 기능과 서비스를 탑재하기 시작했고 사용자들이 이런 신규 기능과 서비스를 원활하게 사용할 수 있게끔 새로운 입력 UI 방식 을 적극적으로 적용하게 되었다. 특히 음성 인식, 제스처 인 식과 같은 NUI(Natural User Interface) 가 주목을 받으며 경쟁적으로 도입되었다.

새로운 기술이 유행할 때 제품/서비스 공급자는 "기술을 위한 UX"의 유혹을 쉽게 받게 된다. 사용자에 대한 배려보 다는 기술력의 과시용으로 무분별하고 과도하게 만들어지는 $\mathrm{UX}$ 는 대부분 사용자로부터 외면 받게 된다. 차세대 TV의 새로운 인터랙션 경험으로 떠오르는 NUI도 이런 UX 문제 점으로부터 자유롭지는 않다.

$\mathrm{UX}$ 담당자는 TV의 여러 사용 경험들 중 어떤 것들이 $\mathrm{NUI}$ 에 적합한지 세심하게 파악하여 적절한 선에서 새로운 $\mathrm{UI}$ 기술을 활용함으로써 전체적인 TV의 사용 경험을 높이 는 접근을 해야 한다. 본 연구는 카메라 기반의 비접촉 제스 처 인터랙션에 대해 AHP 기법에 의거한 전문가 대상 설문 조사를 통해 어떤 사용 경험들이 제스처 인터랙션과 어울리 는지를 조사하였다.

음성 인식, 얼굴 인식과 같은 다른 NUI에서도 유사한 조 사가 필요하다. 또한 이미 나와 있는 제품들에 대해 UT (Usability Testing)나 관찰, 설문 등을 통해 적절한 NUI 기반 UX의 범주와 한계가 어디인지를 규명하는 것도 향후 연구 과제로서 수행되어야 할 내용이다.

\section{References}

Bak, J. H., Kang, M. K., Lee, K. T. and Lee, J. S., "Trend Analysis of Gesture Recognition and NUX", Korean Society for Internet Information, vol. 12, no. 4, 2011.12

Choi, S. W., Han, J. H. Lee, G. H., Lee, N. R. and Lee, W. H., "RemoteTouch: Touch-screen-like interaction in the TV viewing environment", ACM CHI, 2011.

Gu, M. J., "Interface Design Guideline for Personalization of Interactive TV Service - Focusing on Skylife's Skytouch Service", Journal of Korean Society of Design Studies, vol. 20, no. 3, pp.129-140, 2006.

Jeong, K. S., "An Outlook on Smart TV", Korea Information and Communications Society - Information and Communication Magazine, vol. 28 , no. $3,2011.2$

Ju, G., "The challenges of designing a user interface for consumer interactive television", IEEE International Conference on Consumer Electronics, 1994.

Kim, E. J., Song, S. Y., Song, W. M. and Kim, M. W., "Personalized User Interface for IPTV", Korea Computer Congress, vol. 36, no. 1, pp.366-371, 2009.

Kim, J. D., "The Operationalization of Evaluation Elements for User Interface Designs of Interactive TVs", Korean Society of Design Studies, vol. 23, no. 5, pp.115-126, 2010.

Lee, K. H., Kim, M. C. and Lee, W. H., "A Review of UI Technologies for Improving Smart TV UX", The Korean Institute of Information Scientists and Engineers, 2011.8

Lekakos, G., Chorianopoulos, K. and Spinellis, D., "Information systems in the living room: a case study of personalized interactive TV design", Euro. Conf. on Information System, 2001.

Park, J. B., "The Future of Smart TV in respect to Consumers' Use Behavior", KT Advanced Institute of Economics, 2011.

Song, M. J., "Market Trends in Smart TV", Semiconductor Insight Magazine, 2010.9.

Yun, M. W., "The Future of TV UX: Communication between Emotion and Technology", Digieco Focus, 2012.4.

\section{Author listings}

Sung Woo Kim: caerang@gmail.com

Highest degree: MS, Information Design \& Technology, Georgia Institute of Technology

Position title: Manager, Centralized Research Lab, Advanced Institute of Technology, KT

Areas of interest: HCI, UI, UX, Consumer Experience in Television 
Date Received : 2012-07-26

Date Revised : 2012-08-07

Date Accepted : 2012-08-07 